\title{
Teatro, tecnologias e educação em perceptos e afectos inovadores.
}

\author{
MÁRCIA FUSARO
}

\begin{abstract}
Márcia Fusaro possui Pós-Doutoramento em Artes pela Universidade Estadual Paulista Júlio de Mesquita Filho (UNESP), com pesquisa sobre educação, teatro e novas tecnologias na contemporaneidade; Doutora em Comunicação e Semiótica pela PUC-SP; Mestre em História da Ciência pela PUC-SP; Especialista em Língua, Literatura e Semiótica; Bacharel em LetrasTradutor e Intérprete, com licenciatura plena em língua portuguesa e inglesa. Atualmente é professora e pesquisadora da Graduação e da Pós-Graduação Scricto Sensu em Gestão e Práticas Educacionais (PROGEPE). Líder de Pesquisa do Grupo Artes Tecnológicas Aplicadas à Educação (CNPq - UNINOVE). Membro de Conselho Editorial (Tesseractum Editorial; Editora COD3S). Editora da Revista Dialogia (2016-2019), vinculada ao Programa Scricto Sensu em Gestão e Práticas Educacionais (PROGEPE), da Universidade Nove de Julho. Pesquisadora das interfaces epistemológicas entre Educação, Arte, Comunicação e Ciência.
\end{abstract}

Afiliação: Universidade Nove de Julho Lattes: http://lattes.cnpq.br/9530154078991445

Orcid: https://orcid.org/0000-0002-1246-9282 


\section{- RESUMO}

Este artigo percorre algumas reflexões em nível epistemológico e empírico sobre o teatro, enquanto busca compreender melhor como estaria se dando, nesse basilar território da Arte, o emprego dos conceitos ligados ao teatro em interfaces com tecnologias criadoras de novos perceptos e afectos na arte contemporânea em diálogo com a educação. Interceptando-se o cenário da pandemia, iniciado em 2020, acrescenta-se, ainda, a urgência de maiores reflexões sobre a criação e a prática de novas linguagens. Isso porque, dentre outros expedientes proporcionados pelos mais recentes usos das novas tecnologias, passaram a fazer parte integrante do teatro e da educação também as redes sociais, as aulas e os eventos on-line, pensados nos contextos das interações não presenciais do período pandêmico. Gilles Deleuze e Antonin Artaud nos conduzem como pensadores referenciais, por entendermos ambos também como educadores, no sentido de haverem feito escola sobre a criação filosófica e artística voltada à Diferença e à Vida. Acrescente-se, ainda, o fato de que no novo cenário pandêmico, lido semioticamente, o corpo e a máscara têm sofrido des(re)territorializações, se vistas à luz dos conceitos deleuzeanos de "rostidade" e "corpo sem órgãos", este último inspirado em Artaud.

PALAVRAS-CHAVE:

Educação, arte, teatro, performance, novas tecnologias.

\section{- ABSTRACT}

This article goes through some reflections at the epistemological and empirical level on theater, while seeking to better understand how the concepts related to theater would be taking place in this fundamental territory of Art in interfaces with technologies that create new percepts and affects in contemporary art in dialogue with education. Intercepting the pandemic scenario, which started in 2020, the urgency of further reflections on the creation and practice of new languages is added. This is because, among other devices provided by the most recent uses of new technologies, social networks, classes and online events also became an integral part of theater and education, designed in the context of non-face-to-face interactions during the pandemic period. Gilles Deleuze and Antonin Artaud lead us as referential thinkers, as we understand both as educators, in the sense that they have made a school about philosophical and artistic creation focused on Difference and Life. Add, still, the fact that in the new pandemic scenario, read semiotically, the body and the mask have suffered de (re) territorialization, if seen in the light of the Deleuzian concepts of "faciality" and "body without organs", this last one inspired by Artaud.

\section{- KEYWORDS:}

Education, art, theater, performance, new technologies. 


\section{Introdução'}

\begin{abstract}
O teatro surgirá como o que não representa nada, mas apresenta e constitui uma consciência de minoria, enquanto devir-universal, operando alianças aqui ou ali

conforme o caso, segundo linhas de transformação

que saltam para fora do teatro e assumem uma outra forma, ou se reconvertem em teatro para um novo salto.
\end{abstract}

(DELEUZE, 2010, p.64)

A linguagem do teatro é em suma a linguagem do palco, que é dinâmica e objetiva. Ela participa de tudo aquilo que pode ser posto sobre um palco em matéria de objetos, de formas, de atitudes, de significações. Mas isto à medida que todos esses elementos se organizam e, ao se organizarem, se separam de seu sentido direto, visando criar assim uma verdadeira linguagem criada no signo em vez de na palavra.

(ARTAUD, 2014, p.72)

No conjunto da obra de Gilles Deleuze, destaca-se a admirável afirmação de que filosofia, ciência e arte são igualmente criadoras. Alia-se a isso o fato de que as descobertas e os novos alcances científicos possibilitam a revisão de posicionamentos, abrindo espaço para um diálogo constante entre as diversas áreas do conhecimento. Nesse amplo, complexo contexto, a relação entre arte e ciência foi se tornando mais estreita com o passar do tempo, uma vez que a arte iniciou uma espécie de absorção das descobertas científicas. Um desses contextos evidenciou-se com as novas possibilidades de uso de linguagens surgidas a partir dos novos posicionamentos sobre a captura do tempo resultantes da invenção da fotografia e do cinema, por exemplo.

É possível, portanto, perceber as artes como adeptas dos debates científico, filosófico e artístico sobre as questões tecnológicas, aqui entendidas no sentido da raiz grega techné (técnica, ofício, arte), acrescido de logia (estudo). Debate este iniciado na segunda metade do século XX e intensificado, sobretudo, neste início de século XXI, pelos novos e reveladores usos de recursos tecnológicos (dispositivos móveis, redes sociais, big data, entre outros), que nos remetem a novas possibilidades de entendimento sobre as relações humanas com as máquinas.

O conceito de máquina é visto por Deleuze por meio de reterritorializações que a situam para além dos sentidos que lhe são atribuídos pelo contexto de pósrevolução industrial. "Máquinas desejantes" é um dos conceitos usados por Deleuze que nos serve também para (re)pensar o papel das novas tecnologias, sobretudo no período atual da pandemia em que tanto as artes quanto a educação estão sendo obrigadas a se reinventar. Também os conceitos de "rostidade" e de "corpo sem órgãos", este último adotado por Deleuze a partir de Artaud, servem como reflexão sobre os possíveis sentidos interfaceadores entre máquinas, humanos, teatro e educação no contexto pós-dramático, para lembrar o termo empregado por Carminda Mendes André (2011) ao se referir ao teatro contemporâneo.

É sabido que em suas manifestações discursivas bastante particulares, o

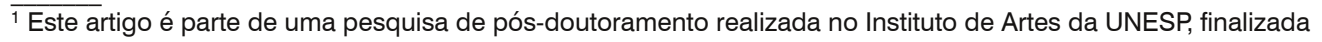
no segundo semestre de 2020.
} 
teatro incorporou, desde sempre, o uso da tecnologia em seus processos de criação e encenação. Lembre-se, por exemplo, do Deus ex machina surgido no teatro grego, em que o ator a representar alguma divindade era descido até o palco por um guindaste. Tudo isso com o intuito de produzir novos espaços semióticos re(des)territorializadores dos papéis do cenário e da atuação do ator. Nesse contexto, entende-se, também conforme Carminda Mendes André (2011), que o corpo carrega possibilidades de se desorientar em sua manifestação biológica, forçando novos limites na percepção. Isso posto, pode-se dizer que "o corpo foi transformado em instrumento tecnológico para a suposta ampliação da percepção e transformação da subjetividade" (ANDRÉ, 2011, p. 90).

Nesse sentido, busca-se aqui um melhor entendimento, evidentemente que não definitivo, sobre algumas aplicações das novas tecnologias nas abordagens mais recentes sobre performance e no assim chamado teatro expandido, termo inicialmente cunhado por Rosalind Krauss (1979). Conceitos estes aos quais voltaremos adiante. As possibilidades de diálogo entre a arte e a educação, em seus aspectos alfabetizadores dos sentidos, são vistos aqui como necessários diante dos contextos dessensibilizadores detectados na educação contemporânea ainda devedora, em grande medida, de saídas inteligentes e criativas quanto a possíveis usos potencializadores do teatro, bem como de outras artes, interfaceadas às novas tecnologias no contexto escolar.

Para fundamentar tal percurso, elege-se o filósofo Gilles Deleuze não por acaso, mas pelo fato de sua lente intelectual considerar filosofia, ciência e arte como igualmente criadoras. A relação máquina versus sujeito pode adquirir novos e diferenciados matizes pelo olhar deleuzeano, inferindo novas reflexões sobre aspectos não necessariamente antagônicos, mas complementares, em suas extensões relacionadas à arte, em especial ao teatro como máquina desejante educadora. Em contextos em que, por exemplo, antes da pandemia de 2020, ainda se testemunhavam proibições de uso do celular nas aulas presenciais, vê-se agora, por força das circunstâncias, todo um novo quadro pedagógico a lidar (forçosamente, ou não) com o virtual. Ou, ainda, retomem-se outros contextos escolares que insistem em considerar as artes como mera "perfumaria", entre tantas outras questões que urgem maiores reflexões na educação. Pelo viés deleuzeano, é possível pensar novas ações em que uma minoria ciente dos potenciais (trans)formadores da arte, em diálogo com dispositivos tecnológicos interfaceados às linguagens teatrais possam se inserir no contexto da escola, sinalizando, quem sabe, um devir-minoritário universal. Nesse sentido, ressalte-se que "minoria não designa mais um estado de fato, mas um devir no qual a pessoa se engaja. (...) Um devir-minoritário universal" (DELEUZE, 2010, p. 63).

O poeta, ator e dramaturgo Antonin Artaud, em sua voz-minoria portadora de devir-maioria, nos serve igualmente de interlocutor por ser também um pensador caro a Deleuze. Afinal, foi nele que o filósofo se inspirou, em parceria com Guattari, para a criação do "corpo sem órgãos", destacável na filosofia deleuzeana, sendo este "não uma noção ou um conceito, mas antes uma prática, um conjunto de práticas" (DELEUZE e GUATTARI, 1996, p.9). Assim, lança-se mão também de uma leitura atualizadora de Artaud, enveredando pelo estudo das novas linguagens vinculadas ao corpo e à vida, naquilo que comportam como extensões para além de ambos (orgânico versus inorgânico), proporcionadas pelo teatro quando 
interceptado, em alguma medida, pelas novas tecnologias.

Deleuze e Artaud são, sobretudo, afirmadores da Vida. À luz de uma tal perspectiva, considerem-se, portanto, as contextualizações conceituais anteriormente elencadas. Direcionadas, ainda, a questões que emergem e se encaminham para como estariam sendo (in)viabilizadas as (im)possíveis aproximações entre $o$ humano e a máquina no campo da arte teatral contemporânea em percursos bem-pensantes e criativamente aplicados na área da educação. Propõem-se, assim, algumas reflexões de cunho epistemológico e empírico sobre o teatro como agente formador e transformador na educação contemporânea, incluindo-se possíveis diálogos com as novas tecnologias, evidentemente que sem a pretensão de esgotar tema tão vasto e complexo.

\section{Art(e)audeleuzear}

Artaudeleuzear é entender a arte como campo de imanência resistente e potencializador da existência entendida como Vida, com $V$ maiúsculo. Afinal, é o próprio Deleuze quem nos lembra de que "a arte é o que resiste: ela resiste à morte, à servidão, à infâmia, à vergonha” (1992, p. 215).

Deleuze e Artaud são, conforme dissemos, afirmadores da Vida. Nessa esteira, também podem ser entendidos como educadores. Cada um com seu estilo muito particular de reverenciar a Vida. "O verdadeiro teatro, porque se mexe e porque se serve de instrumentos vivos, continua a agitar sombras nas quais a vida nunca deixou de fremir" (ARTAUD, 2006, p.7). "Dir-se-á da pura imanência que ela é UMA VIDA, e nada além disso. Ela não é imanência à vida, mas a imanência que em nada é, ela própria é uma vida. Uma vida é a imanência da imanência, a imanência absoluta: ela é potência, beatitude completas" (DELEUZE, 2016, p. 409). Vale lembrar que Spinoza e Nietzsche, entre outros pensadores fundamentais, perpassam esses tecidos de leitura, mas não cabem no recorte deste artigo.

Artaudeleuzear é, ainda, pensar a arte como máquina desejante de Vida geradora de afectos e perceptos em devires potencializadores da criação de um corpo sem órgãos. Para Deleuze, junto a Guattari, seu grande parceiro intelectual, a arte é independente de seu criador e se conserva em si mesma como "um bloco de sensações, isto é, um composto de perceptos e afectos. (...) As sensações, perceptos e afectos, são seres que valem por si mesmos e excedem qualquer vivido" (DELEUZE; GUATTARI, 1992, p. 213. Grifos dos autores). É ao "gênio esquizofrênico" de Artaud que ambos recorrem para criar o "corpo sem órgãos", definido mais como uma prática ou máquina de guerra de resistência, do que propriamente um conceito (DELEUZE; GUATTARI, 1996, p. 9-29).

A precisa definição de Regina Schöpke (2017) afirma que o corpo sem órgãos não se trata de uma negação de si nem de autodestruição, mas de uma busca desesperada pelas intensidades que foram roubadas do organismo para servir a forças que não são aquelas da vida. Nesse sentido, Artaud e Deleuze podem ser lidos como educadores para a Vida, para a potência do viver. O corpo sem órgãos em devir-revolucionário pleno, ainda nessa esteira, é aquele que se faz máquina de guerra de resistência reafirmadora da Vida, do desejo de viver. $\mathrm{E}$ do que se trata o teatro, profundamente entendido e praticado por Artaud, senão isso 
também? Teatro nômade, permanente reinventor de si mesmo e, por consequência, da própria vida e da própria arte. Em termos artaudeleuzeanos, um teatro a lidar com o corpo constituído, ele mesmo, como máquina de guerra a serviço da Vida, de novos perceptos e afectos, como somente a arte fadada a permanecer sabe se constituir e fazer.

\section{Teatro educador dos sentidos: exercícios em primeira pessoa}

Por conta do caráter descritivo envolvido neste segmento, solicito permissão para assumir, brevemente, o relato em primeira pessoa. $O$ intuito é contribuir, de alguma forma, com ideias que possam inspirar novas práticas a partir de certos afectos e perceptos por mim vivenciados ao longo de uma recente pesquisa de pósdoutoramento.

A participação no grupo de pesquisa Performatividades e Pedagogias (UNESP-CNPq) tem me proporcionado momentos singulares de aprendizagem sobre o teatro em diálogo basilar e criativo com a educação ao longo dos últimos anos. Ilustra também o exemplo de uma convivência proativa entre pesquisadores criticamente atualizados e atentos às questões de seu tempo. Carminda Mendes André, coordenadora do grupo pelo Instituto de Artes da UNESP, aponta em seu livro Teatro pós-dramático na escola (2011) que são diversos os questionamentos ligados às crises conceituais e práticas em que a arte é vista no contexto educacional. Por esse olhar, acrescentado àquele voltado à prática do teatro ligado à educação como Vida, caudatário, portanto, daquilo que destacamos anteriormente em Deleuze e Artaud, vivi acontecimentos (para lembrar Deleuze), como prática de Vida ao longo de uma pesquisa compartilhada em convivência com o grupo entre 2018 e 2020, e do qual tenho a felicidade de continuar a participar como colaboradora. Muitos seriam os exemplos, mas, por questões de espaço, destacarei dois a seguir.

a) Aula prática, baseada em leituras de Deleuze e Artaud, sobre os conceitos de "rostidade" e "corpo sem órgãos".

O exercício de preparar e aplicar uma aula prática ao grupo, em 2019, proporcionou-me um melhor entendimento sobre os possíveis alcances educacionais de ambos os conceitos (rostidade e corpo sem órgãos) interfaceados à poética do teatro. Considerando-se o interesse de Artaud também pelo teatro oriental, presente em seu livro o Teatro e seu Duplo (2006), foi possível acrescentar um toque a mais de experimentação à aula, com música e relaxamento, além da incorporação de elementos do teatro e dança indianos e da poesia haicai japonesa. Máscaras minimalistas, improvisadas com sulfite e dois orifícios apenas no lugar dos olhos dos participantes serviram como parte do instrumental. Em um dos vários exercícios praticados, os participantes sentaram-se em duplas, um de frente para o outro, segurando a máscara de sulfite diante do rosto enquanto tentavam traduzir somente pelo olhar trechos de haicais lidos por mim em voz alta. Na etapa seguinte, dessa vez sem as máscaras, duplas reorganizadas em novos pares lançaram mão somente da expressão facial (rostidade) para interpretar minha leitura de uma nova 
série de haicais.

A perspectiva tecnológica e concretizou por meio do uso do celular para captura de expressões e imagens singulares durante a aula ligadas, de alguma forma, à temática da "rostidade" e do "corpo sem órgãos". Uma roda de conversa, ao final das duas horas de práticas cujas descrições não cabem todas aqui, proporcionou importantes feedbacks do grupo, não somente sobre as repercussões dos exercícios para cada um, mas também sobre como seriam tais possibilidades de trabalho adaptadas a uma sala de aula nos diferentes níveis de ensino.

b) Participação em exercício prático de performance.

No mesmo ano de 2019, participei de um exercício prático, baseado no conceito de "erratório", desenvolvido por colegas participantes desse mesmo grupo da Unesp, mas também pertencentes ao grupo de teatro performático Parabelo. Esse exercício performático de alto impacto sensorial é descrito abaixo com o intuito de servir, quem sabe, como modelo de inspiração a outros tantos, a depender dos critérios de cada contexto e espaço escolar.

Sem muitos detalhes prévios (sendo isso parte do exercício) sobre como seria o andamento da performance, permaneci vendada, ao longo de uma hora, enquanto era conduzida por uma componente do grupo Parabelo, ambas em silêncio, desde o interior da estação Barra Funda do metrô de São Paulo, passando pelo terminal de ônibus, até o prédio do Instituto de Artes da UNESP, localizado próximo à estação. No trajeto, guiada somente por leves toques das mãos da minha colega e sem nos falarmos, eu ia ouvindo as repercussões da interação com as pessoas ao redor. Vendedores ambulantes e transeuntes curiosos tiveram diversos tipos de reações e interações com o que estávamos fazendo. Sem dúvida, essa foi uma das experiências mais impactantes que tive ao longo desta pesquisa. Na última parte, já no prédio do Instituto de Artes, o grupo desenvolveu uma série de novos exercícios ligados à poética sensória com todas as duplas (cerca de seis) que participaram do mesmo exercício. Reproduzo, a seguir, o texto que elaborei, cuja escrita foi solicitada a todos naquele dia, como parte integrante do exercício:

"O que eu olho, o que me olha": surpresa, insegurança, tatear, respiração. Sons distantes, próximos. Encontros. Ritmos de passos. Delicadeza do toque. Cuidado. Segurança. Ritmo dos passos. Cadência. Segurança nova. Texturas. Pés (queria estar descalça). Odores. Vozes. Num piscar, o perigo. Motores. Calor de motores. Nova (in)segurança. Sonoridades de cheiros. Sabores de passos. Lentos. Parados. Retomados. Ritmados. Apressados. O risco. As vozes. Um "obrigada". Um "de nada". Cimento raspante. Grama macia. Barro mole. "Quando chega?" Tempo longo. Eternidade de tempo. Ritmo de passos. Conjuntos. Mesmos passos. Descompasso. "Quando chega?" Silêncio. Torpor. Silêncio. Conforto. Sonolência. Passos. Arranhar de parede. Descer, subir degraus. Delicadeza do tato. Calor. Ritmos de passos. "Quando chega? Se não chegar, não 
tem problema. Então é assim (ou quase assim) a cegueira da minha aluna? Um beijo a você, Roberta". Grama. Barro fofo. "Quando chega?" Ritmo. Passos. Vento nos cabelos. No rosto. "Vou tirar sua venda". Desvenda. Sorrisos. Olhares de saudação. Que alegrias o rever. Revê-los. Um beijo em cada um. Vocês são ótimos!

Ambientes laboratoriais como esses, aproximadores dos signos verbais e não verbais da linguagem, são capazes de proporcionar sensível gama de leituras e trocas de ideias, além de necessárias reflexões sobre possibilidades de novos agenciamentos semióticos entre o teatro e a educação. Após o exercício, lembrome de haver passado os primeiros dias ainda sob o efeito sensorial impactante do exercício, resultante da minha nova referência de fruir o mundo naquele dia.

\section{Mascar(a)rte}

Nada alheio às oportunidades oferecidas pelos contextos de cada época, o teatro, considerado de uma perspectiva semiótica, é assimilador sígnico de outras áreas. Fotografia e cinema, desde seus surgimentos, na segunda metade do século XIX, passando pelo rádio e a televisão, ao longo do século $\mathrm{XX}$ e, mais recentemente, a informática e seus desdobramentos, intensificados desde a virada do século XXI, têm vivido momentos de confluência com o teatro. No contexto-limite da pandemia, evento marcante deste início de século, o teatro tem recorrido, a exemplo de outros campos artísticos, às apresentações on-line em mídias sociais, estabelecendo novas e criativas concepções em face das necessidades impostas pela quarentena. Exemplo disso é o projeto Teatro em Movimento Digital, que é parte de um projeto maior promovido pela Rubim Produções (2020), com sede em Belo Horizonte (MG), com espetáculos on-line, além de cursos e outras abordagens voltados aos vínculos possíveis entre o teatro e as novas mídias e plataformas digitais. Afinal, recorrendo mais uma vez a Deleuze, "a arte é o que resiste" (1992, p. 215), e o teatro tem sido, desde sempre, um dos principais campos de resistência artística. Nesse sentido, não se trata, portanto, de ousadia afirmar que o alcance dos sentidos humanos se expandiu exponencialmente a partir dos usos dessas mídias tecnológicas mais recentes e que as manifestações de arte, especialmente aquelas do teatro, aqui em recorte, já não se separam tão confortavelmente nas abordagens modernas e contemporâneas.

Ao se incluir nesse contexto o diálogo entre teatro e educação, entendendo as novas tecnologias como interceptadoras de agenciamentos potencializadores de seus ambientes sígnicos, surge todo um novo quadro de possibilidades de reflexões atualizadoras solicitadas para a arte e a educação. O contexto-limite da pandemia de 2020, nem é preciso dizer, acentuou ainda mais a necessidade de tais reflexões. Sobretudo diante de vídeos que, por exemplo, no início da quarentena, mostravam nas mídias sociais alguns professores com suas câmeras de celular ligadas diante de lousas onde, tensos, escreviam suas aulas.

A máscara e o trágico sem dúvida também adquiriram novos alcances semióticos resultantes do cenário pandêmico. Obrigatório planeta afora, o uso da máscara tem se caracterizado como uma espécie de teatro social, às vezes trágico, 
às vezes tragicômico, até mesmo do absurdo. Este último, bem entendido, em sentido literal. Longe do bem-vindo vanguardismo de um Beckett. Entendida como signo de mistério desde remotos ritos ancestrais, a máscara tem se re(des)territorializado em nível planetário. Signo-limite de vida e morte, foi também transformada em personagem nesse trágico teatro pandêmico que ora vivemos.

A máscara se re(des)territorializa também, contemporaneamente, como instrumento de poder. O poder em nível macro, exercido por (des)lideranças nos mais variados níveis, bem como os meandros em que o poder atua em nível microfísico, para lembrar Foucault (1979), têm lançado mão de manobras discursivas relacionadas às máscaras, dentre outras questões pandêmicas que não cabem aqui serem discutidas. De fato, a máscara transformada em personagem tem revelado mais ao longo dos últimos meses, do que propriamente ocultado, os agenciamentos éticos e estéticos desse trágico teatro pandêmico. Afinal, "dê uma máscara ao homem e ele dirá a verdade" já nos dizia a fina ironia de Oscar Wilde no século XIX, em sua obra Intentions (1891).

Desde As Bacantes, tragédia considerada a mais brilhante de Eurípides, vencedora de um dos Festivais Dionisíacos no século V a.C., o complexo signo da máscara se tornou personagem à parte, utilizada por ninguém mais, ninguém menos, do que o próprio Dioniso, deus do vinho e do teatro, posto em cena nessa peça. No enredo, repleto de ironia trágica, Dioniso se transforma em atorpersonagem ao se disfarçar de mortal e se apresentar desempenhando seu próprio papel de deus do teatro, usando sua própria máscara e indumentária por meio do artifício do deus ex machina.

Para não ficarmos somente no contexto grego, lembremos, de passagem, que a máscara também se faz presente em outros contextos e culturas. Tanto quanto as máscaras do teatro grego, também se mascara, por exemplo, o rosto japonês no teatro Nô, conforme nos apresenta Roland Barthes na deslumbrante poética filosófica de seu O Império dos Signos (1970). Ainda, segundo o pensador, a máscara se desenha no Kabuki. Artificializa-se no Bunraku. E mediante duas substâncias: o branco do papel e o negro reservado à inscrição dos olhos. Desta enunciação barthesiana, como não lembrar também o conceito de rostidade do muro branco-buraco negro sob o efeito da máquina abstrata de Deleuze e Guattari? Ainda que se trate do rosto, lembremos que é nele que se fixa a máscara. Persona. Por esse viés, rostidade e mascaramento se compatibilizam, mais do que nunca, se considerados pelo devir dos agenciamentos pandêmicos. Conforme dito, enquanto tenta (se) mascarar, a pandemia tem, ao mesmo tempo, servido para revelar. Incluindo-se os mais recentes e emergenciais usos das redes sociais como instrumentos midiáticos para resgates de interação social nos mais variados, inusitados, às vezes até mesmo risíveis, cenários.

Movido pela nova ironia do trágico, reterritorializa-se o próprio conceito de teatro, transformado em ambiente virtual por estes nossos tempos desafiadores. $\mathrm{Na}$ cena teatral, onde a presença física sempre ocupou primordialmente a aura artística, outrora já anunciada por Walter Benjamin (1935), vê-se agora, pela imposição do contexto, performances de artistas, não somente de teatro como das mais variadas instâncias, sendo transmitidas por meio de incontáveis lives. Submetem-se, assim, tanto a presença física quanto a virtual, aos novos agenciamentos pandêmicos, e a alguns poucos cliques de distância de congressos, seminários e outros eventos 
acadêmicos on-line, às vezes aproximando virtualmente pessoas de várias partes do mundo, para tratar sobre os rumos possíveis de cada setor. Ressalte-se, no entanto, de que não é a primeira vez que o teatro se vê desafiado a interagir com novas mídias. Entre as décadas de 1920 e 1930, no ensaio "Teatro e rádio" (2017), fruto de reflexões desenvolvidas ao longo de seu trabalho radiofônico, Walter Benjamin já anunciava possíveis cenários de problemas e colaborações entre esses dois campos.

O mais inusitado do que se vê agora, nesse atual cenário pandêmico que vivemos, é o fato de, em questão de semanas, nos mais variados contextos, a privacidade do ambiente doméstico haver se transformado em cenário virtual das mais belas, inteligentes, inspiradoras até as mais dispensáveis e estapafúrdias encenações. Tornamo-nos testemunhas de incontáveis possibilidades de convivências virtuais tanto libertadoras, quanto extenuantes: reunião de trabalho, sala de aula, palco de espetáculo, supermercado, palanque político, divã de psicanalista, entre tantas outras "encenações", com ou sem máscara, que poderiam ser aqui mencionadas.

\section{Considerações finais}

Partindo da proposta de algumas reflexões sobre o teatro e a educação em diálogos de alcances epistemológicos e empíricos, detectamos novos agenciamentos narrativos teatrais no contexto contemporâneo, além de possíveis interfaces com as novas tecnologias interceptadoras do debate científico, filosófico e artístico. Conduzidos pela aura do pensamento de Deleuze e Artaud, buscamos apontar certas des(re)territorializações relativas ao teatro contemporâneo, naquilo que também alcançam nas interfaces escolares, perseguindo o conceito fundamental do teatro como agente formador e transformador na educação contemporânea, mesmo que em um contexto-limite fadado temporariamente às interações virtuais como aquelas vividas por consequência da pandemia iniciada em 2020.

Diante das inúmeras re(des)territorializações causadas pela tragédia pandêmica atualmente vivida, é urgente que se busque a possibilidade de ações em novos agenciamentos. Enfim, reterritorializações de UMA VIDA imanente, conforme o sublime sentido enunciado no último texto escrito por Deleuze, e também reivindicado ao longo de toda a vida-obra de Artaud. Vida como potência criativa voltada a se reinventar mesmo que diante dos mis desafiadores cenários. Vida como acontecimento. Incluindo-se nisso novos agenciamentos semióticos voltados à arte teatral em diálogos criativos com a educação e os novos instrumentos tecnológicos.

As perspectivas de Deleuze e Artaud nos incitam não somente a refletir sobre nossa condição e nossos papéis neste palco pandêmico, mas cobram, sobretudo, ações cotidianas que se justifiquem ao serem aplicadas na vida que busca UMA VIDA. Por isso, para além de lamentarmos (não sem razão, diga-se de passagem!) o que estamos vivendo, optemos, ao contrário, com muito mais potência por novas ações criativas, mesmo que tal escolha implique em ter de abrir mão de certas atitudes, vínculos, cenários e máscaras que insistimos em considerar fundamentais e imutáveis. Afinal, além da Arte, a Vida também é o que resiste. 


\section{Referências}

ANDRÉ, Carminda Mendes. Teatro pós-dramático na escola. São Paulo: Ed. Unesp, 2011.

ARTAUD, Antonin. Linguagem e vida. São Paulo: Ed. Perspectiva, 2014.

O teatro e seu duplo. São Paulo: Martins Fontes, 2006.

BARTHES, Roland. O império dos signos. São Paulo: Martins Fontes, 2016.

BENJAMIN, Walter. A obra de arte na era de sua reprodutibilidade técnica (primeira versão de 1935). In: . Magia e técnica, arte e política. Obras escolhidas vol. I. São Paulo: Brasiliense, 2012.

Teatro e rádio. In: Estética e sociologia da arte. Belo Horizonte: Autêntica, 2017.

DELEUZE, Gilles. Sobre o teatro. Rio de Janeiro: Zahar, 2010.

Dois regimes de loucos. São Paulo, Editora 34, 2016.

Mil platôs: capitalismo e esquizofrenia (Vol. 3). São Paulo: Editora 34, 1996.

Conversações. São Paulo, Editora 34, 1992.

DELEUZE, Gilles; GUATTARI, Félix. O que é a filosofia? São Paulo: Editora 34, 1992.

Mil Platôs. Vol. 3. São Paulo: Editora 34, 1996.

FOUCAULT, Michel. Microfísica do poder. Rio de Janeiro: Edições Graal, 1979.

KRAUSS, Rosalind. Sculpture in the Expanded Field. October. Vol. 8., pp. 30-44, 1979.

RUBIM PRODUÇÕES. Teatro em Movimento Digital. Belo Horizonte-MG, 2020. Disponível em: https://teatroemmovimento.com.br/teatro-em-mov-digital/ (Acesso em 21/04/2021).

SCHÖPKE, Regina. Corpo sem órgãos e a produção de singularidade. Aurora. Curitiba, v. 29, n.46, p.259-279, jan/abr 2017.

WILDE, Oscar. Intentions. (Public domain). Cornell University. Heinemann and Balestier Limited, 1891.

Recebido em 29/04/2021 - Aprovado em 15/08/2021 
Como citar:

FUSARO, M. C. F. Teatro, tecnologias e educação em perceptos e afectos inovadores. ouvirOUver, v.17, n.2. p. 257-268. jul./dez. 2021. https://doi.org/10.14393/OUV-v17n2a2021-60789

(c) (7) A revista ouvirOUver está licenciada com uma Licença Creative Commons Atribuição-NãoComercial 4.0 Internacional. 